\title{
ISS outreach Sub-Saharan Africa insight: Uganda 2011
}

\author{
Johnny U. V. Monu • Zeridah Muyinda • Mihra Taljanovic
}

Received: 19 July 2012 /Revised: 19 July 2012 / Accepted: 19 July 2012 / Published online: 17 August 2012

(C) ISS 2012

\section{Introduction}

Uganda has a vibrant radiology organization and this was explored with the result of an outreach effort being directed to Uganda. An outreach activity was organized in collaboration with the Association of Radiologists of Uganda (ARU) at the campus of Makerere University School of Medicine from 8-10 September 2011.

Uganda is a landlocked country in East Africa with Kenya on its eastern border, the Democratic Republic of the Congo to the west, Southern Sudan to the north, Rwanda to the southwest, and Tanzania to the south. Lake Victoria, which is also shared by Kenya and Tanzania, lies to the south. Uganda with a population of 36 million is multi-tribal including the Baganda (16.9\%), Banyakole (9.5\%), Basoga (8.4\%), Bakiga (6.9\%), Iteso (6.4\%), Langi (6.1\%), Acholi (4.7\%), Bagisu (4.6\%), Lugbara (4.2\%), Bunyoro (2.7\%), and others $(29.6 \%)$ [1].

Uganda has a literacy rate of about $74 \%$. The average expenditure on health is $8.2 \%$ of the GDP and per capita income is $\$ 1,317$ [1,2]. The physician density is about 0.12 per 1,000 and the hospital bed density is 0.4 per 1,000 . Infant mortality rate is 63 per 1,000 . The average life expectancy is 53.45 years (52.4 men and 54.54 female) [1].

J. U. V. Monu (凶)

Department of Imaging Sciences, University of Rochester, Rochester, NY 14246, USA

e-mail: johnny_monu@urmc.rochester.edu

Z. Muyinda

Mulago Medical School, Makerere University,

P.O. Box 7062, Kampala, Uganda

M. Taljanovic

University of Arizona,

Tucson, AZ, USA

\section{Medical education}

There are five medical schools in Uganda; namely, Makerere university in the capital city Kampala, Mbarara university in the western region, Gulu university in the northern region, Busitema university in the central region, Kampala international university, Kampala in the central region and another campus in the western region and Nsambya in the central region. The first three are government owned while the other two are private. Medical school training is modeled after the British system where medical school is 5 years of training after high school. Graduation is followed by 1 year of rotating internship in the core clinical disciplines of medicine, surgery, obstetrics and gynecology, and pediatric. Postgraduate training in radiology comprises 3 years of training leading up to a masters degree in radiology. Makerere and Mbarara National Referral and Teaching universities are the only ones offering a master of medicine degree in diagnostic radiology.

Master of Medicine in Diagnostic Radiology takes 3 years. The training modes include lectures, tutorials, practicals, course work, research and assessment. The assessment entails oral, practical and theory examinations. The course units are Radiological Physics, Photography, Radiological Anatomy, Special Radiological Techniques, Clinical Radiology, Clinical Case Description, Nuclear Medicine and Radio-oncology, Interventional Radiology, Obstetric and Gynecology, Small Parts and Musculoskeletal Ultrasound, Teleradiology and Computer Science, Epidemiology and Biostatistics, Health System Management and Research Methodology. Virtually all the radiologists in Uganda trained locally, with a few having electives in Germany and Macmaster University in Canada.

The government subsidizes health care by providing free health facilities for the population at the government owned hospitals and clinic, but these are grossly inadequate. Large segments of the population have to provide their own health care. The ratio of individual expenditure on health to 
Table 1 Equipment

\begin{tabular}{lccll}
\hline Equipment type & Government health units & Private health units & Total & Comments \\
\hline $\begin{array}{l}\text { Mammography } \\
\text { Fluoroscopy units }\end{array}$ & 2 & 2 & 4 & All are functional. No digital facilities \\
& 27 & 7 & 34 & $\begin{array}{c}\text { All the government based fluoroscopy units are } \\
\text { non-functional and only } 4 \text { are functioning in } \\
\text { private hospitals. }\end{array}$ \\
$\begin{array}{l}\text { Ultrasound } \\
\text { MRI units }\end{array}$ & All government units (150) & Numerous private clinics & There are numerous ultrasound devices all over the country \\
CT units & 0 & 3 & 3 & $\begin{array}{c}\text { Two are functioning at } 0.2 \text { and } 0.3 \mathrm{~T} \\
\text { One is a 16-slice CT in a government owned unit } \\
\text { and the rest are two-slice. One is nonfunctional }\end{array}$ \\
\hline
\end{tabular}

government expenditure is $78.3 \%$ and comparable figures for Great Britain and the USA are $16.1 \%$ and $46.9 \%$ respectively [2]. A large section of the population depends on private clinics for their health care needs.

There are 42 radiologists in Uganda of which only 5 (11.9\%) are purely private practitioners [3]. Twelve of the radiologists $(28.6 \%)$ work outside the capital city as they are posted in district referral hospitals, but still these are urban centers. This gives a ratio of about 1 radiologist per million persons! Subspecialization in radiology is relatively nascent, although some of the radiologists do practice with areas of interest.

\section{Radiography extenders}

Radiography extenders in Uganda are radiographers who have attained a masters degree in medical imaging. They are called imaging technologists. To date there are only 14 of them. They specialize in any of the following: ultrasound, radiotherapy, diagnostic radiography or nuclear medicine. Most have had their training in Uganda and a few in South Africa. In Uganda, there is only one training facility offering these masters courses (Master of Medical Imaging and Master of Diagnostic Ultrasound) for radiography. The Ernest Cook Research and Education Institute ECUREI located at Mengo Hospital, Kampala, is a private entity. It is affiliated to the Thomas Jefferson Ultrasound and Research Institute in the USA and Fontys University in the Netherlands. The training methods used at ECUREI include lectures, tutorials, practical, course work, research, and assessment. It is student-centered learning or problem-based learning.

The major role of the radiography extender in Uganda is to optimize image acquisition and interpret ultrasound examinations where there are no radiologists.

\section{Equipment}

There are numerous radiography machines and CT scanners in Kampala. Away from Kampala the availability becomes scarcer. Ultrasound machines are readily available and widely used. The ultrasound practical was a highlight of the outreach. Table 1 summarizes the equipment available across the country.

\section{Challlenges and the way forward}

Like most sub-Saharan countries, Uganda faces a number of challenges in the field of radiology and imaging. There are still very few radiologists to cover the needs of the entire nation in terms of training and health care service delivery. The training facilities are also inadequate in number and quality. Other challenges include an unstable power supply (responsible for equipment malfunction), and a perennial lack of radiology consumables.

Amidst all these challenges, radiology and imaging in Uganda are still very vibrant and thriving. There is a lot of emphasis on continuous professional improvement and medical education. There are numerous conferences, seminars and workshops that are supplemented with training materials and literature from the internet. The Association of Radiologists of Uganda (ARU) and Makerere University always welcome collaborators or development partners from developed countries. Visiting professors from developed countries are welcome to visit and teach, and demonstrate practical skills at conferences and seminars and in the university teaching hospitals. Textbooks and access to e-learning sites or journals can also be donated to help.

\section{References}

1. Central Intelligence Agency. The World Fact book. Available online at https://www.cia.gov/library/publications/the-world.../geos/ ug.html. Accessed 18 April 2012.

2. WHO. Global Health Observatory Data Repository. http://apps. who.int/ghodata/.

3. Patience Ahimbisibwe, Uganda: Country Has Only 35 Radiologists by Elsie Kiguli (10th Sheffield International Conference at Makerere University). The Monitor. 11 October 2010. 